\title{
Carbonization Law of Fly Ash Concrete under Freeze-Thaw Cycles Based on Image-Pro Plus
}

\author{
Jing Yuan ${ }^{1}$, Boxin Zhao ${ }^{2}$, Zhenqiang Wang ${ }^{3}$, Yan Liu ${ }^{1 *}$ \\ ${ }^{1}$ Urban and Rural Construction Institute, Hebei Agricultural University, Baoding 071001, China \\ ${ }^{2}$ Information Center, Hebei Software Institute, Baoding 071001, China \\ ${ }^{3}$ Beijing Branch, ShanghaiBaoye Group Corp., LTD, Beijing 102600, China
}

Corresponding Author Email: liuyan@hebau.edu.cn

https://doi.org/10.18280/acsm.440604

Received: 15 June 2020

Accepted: 27 September 2020

\section{Keywords:}

IPP, freeze-thaw cycles, ratio of carbonized area (RCA), fly ash concrete, carbonization depth

\begin{abstract}
To understand the influence of freeze-thaw on the carbonization performance of concrete in severe cold areas, this paper conducted experiments to explore the carbonization law of fly ash concrete under freeze-thaw cycles. First, carbonization tests were conducted under different freeze-thaw cycles and fly ash contents; then PS (Photoshop) and IPP (Image-Pro Plus) were adopted to measure the carbonized area and calculate the ratio of carbonized area (RCA). The experimental results showed that, when the fly ash content was between $10 \%$ and $30 \%$, RCA increased slowly; when the fly ash content was $20 \%$, the convergence point showed up; when the fly ash content was 0 , the air-entrained fly ash concrete had the best resistance to carbonation. With the help of PS and IPP, this paper calculated the RCA more accurately and found that, the freeze-thaw cycles can aggravate carbonization, and there is a linear relationship between carbonization depth and RCA. The research findings in this paper can provide a reference for the durability evaluation and design of concrete structures in severe cold areas.
\end{abstract}

\section{INTRODUCTION}

Carbonization is one of the important factors affecting the durability of concrete. Since the early 1960s, China has begun to make great efforts in the study of concrete durability and made great research progress. It is usually believed that concrete undergoes carbonization under general atmospheric environmental conditions, which will cause corrosion of steel bars and ultimately result in insufficient structural durability of the concrete. In cold or severe cold areas, the concrete suffers from freeze-thaw cycles and causes internal cracks or surface peeling off, which will provide favorable conditions for the diffusion of carbon dioxide into its interior, and this is different from the carbonization of concrete under single carbonization condition. Fly ash is a kind of industrial waste residue, now as fly ash concrete is being applied and promoted, its durability problem has become increasingly prominent, which mainly manifested as poor resistance to carbonization and frost, and it is seriously affecting the service life of concrete [1-3].

As for the durability of fly ash concrete under the action of single carbonization or freeze-thaw factor, domestic and foreign scholars have made extensive discussions [4-8] and obtained research results mainly concerning aspects such as the concrete carbonization process and its influencing factors, the prediction of concrete carbonization rate and depth under different fly ash replacement rate, the relationship between fly ash content and carbonization speed, the relationship between carbonization depth and concrete strength, and the damage constitutive model of fly ash concrete under freeze-thaw cycles, etc., and some of these research results have already been applied and promoted in actual projects.
However, the actual environmental conditions of in-service concrete generally contain not only one single condition, Xiao and Gou [9] summarized other conditions that can affect the carbonization performance of concrete, one common condition is the coexistence of freeze-thaw and carbonization, therefore, research on the carbonization performance of concrete under freeze-thaw cycles seems to be particularly important. Some researchers studied the durability of fly ash concrete under the coupling conditions of freeze-thaw and carbonization. For example, Mao et al. analyzed the degradation mechanism of the alternate effects of freeze-thaw and carbonization, and discussed the carbonization depth, the relative dynamic modulus of elasticity, and the mass loss changes; and the mathematical expression of the damage coefficient of composite material $\mathrm{k}(\mathrm{F})$ pointed out that the damage of concrete caused by the coupling effect is more serious than that by a single factor [10-13]; Li et al. [14] pointed out that carbonization can improve the frost resistance of concrete to a certain extent within a reasonable range. Rao et al. used computer tomography (CT) and scanning electron microscope (SEM) to study the microscopic characteristics of fly ash concrete under the alternating effects of freeze-thaw and carbonization $[15,16]$. Kuosa et al. studied the durability of concrete and high ductility ecological cement base with the coupling of freeze-thaw and carbonization taken into consideration $[17,18]$.

Generally speaking, there is few researches on the carbonization law of fly ash concrete under freeze-thaw cycles, and there are even fewer studies concerning the carbonization performance of air-entrained fly ash concrete under freezethaw cycles. In addition, for concrete damaged by freeze-thaw, the carbonization status of its carbonized fracture surface is 
different from the carbonized fracture surface of concrete without freeze-thaw damage, and the carbonation depth measurement method is not accurate enough to study the carbonation law of concrete. Therefore, it is necessary to use a new carbonation indicator to study and analyze the carbonation law of air-entrained fly ash concrete under multiple freeze-thaw cycles.

In order to find a new carbonization indicator to accurately characterize the carbonization performance of concrete, and to obtain the carbonization law of air-entrained concrete under different fly ash contents and different freeze-thaw cycles, this paper designed 5 different kinds of high-performance concrete with different fly ash contents, and carried out freeze-thaw cycle and carbonation tests on them. With the help of IPP and PS, the RCA values of the concrete test pieces were accurately calculated in the paper, and the influence of fly ash content on the carbonization resistance of the concrete was analyzed, the research findings showed that, there's a linear relationship between carbonization depth and the RCA. The research in this paper has practical significance for the design of the durability of hydraulic concrete in severe cold areas.

The content of the paper mainly consisted of four parts: an overview of the experiments, the calculation method for RCA based on IPP, the experimental results and analysis, and the conclusions.

\section{EXPERIMENT OVERVIEW}

\subsection{Preparation of test pieces}

The experiment designed 5 types of fly ash concrete with different fly ash contents of $0 \%, 10 \%, 20 \%, 30 \%$, and $40 \%$, and the water-binder ratio was 0.4 . The design process of the mix ratios was in accordance with the requirements of Specification for Mix Proportion design of Ordinary Concrete (JGJ 55-2011), and the specific mix ratios are shown in Table 1. The experiments used Quzhai (brand name) P.O 42.5 Ordinary Portland Cement, Grade-II fly ash supplied by Baoding mixing plant of Hebei Construction Group, local gravel of Baoding (particle size 5-20mm, continuous gradation), local river sand of Baoding (fineness modulus 2.78), polycarboxylic water reducing agent, PC-2 type liquid rosin pyrolytic polymer air-entraining agent, and tap water. The slump range was $180 \mathrm{~mm} \sim 200 \mathrm{~mm}$, and the extension range was $450 \mathrm{~mm}-550 \mathrm{~mm}$.

To figure out the influence of freeze-thaw cycles on the carbonization law of fly ash concrete, this study designed the contrast tests (carbonization only, CO mode) and the FC cycle tests (cyclic freeze-thaw first and carbonization later, FC mode).

\subsection{Experiment methods and procedures}

The freeze-thaw cycle tests adopted the fast freeze-thaw method, and the equipment was a Naijiuwang (brand name) NJW-HDK-9 microcomputer automatic concrete fast freezethaw device; the carbonization tests adopted the fast carbonization method, and the equipment was a CABRHTX12 type concrete carbonization test box. The tests were carried out in accordance with the Standard for Test Methods of Long-term Performance and Durability of Ordinary Concrete (GB/T 50082-2009).

The abbreviations of the symbols and the basic conditions of the experiments are shown in Table 2.

Table 2 was obtained based on the Fick's law of diffusion, and $\mathrm{Li}$ et al. [19] and Lin and Ou [20]'s studies about the calculation method of the number of test cycles in different regions, and the provisions of the anti-freeze grade. The influence of relative humidity, temperature and sunshine difference on the carbonization of concrete was ignored, the analysis was mainly based on the Fick's law of diffusion, rapid carbonization time/natural carbonization time $=\mathrm{CO}_{2}$ concentration of fast carbonization $/ \mathrm{CO}_{2}$ concentration of natural carbonization, the $\mathrm{CO}_{2}$ concentration of the experiment box of fast carbonization and the $\mathrm{CO}_{2}$ concentration under natural conditions were respectively $20 \%$ and $0.03973 \%$. It can be calculated that F50-C3 and F100-C7 were approximately equivalent to the carbonization time under natural conditions of 4.25 years and 9.75 years, respectively.

Table 1. Mix ratios of fly ash concrete

\begin{tabular}{ccccc}
\hline Group & Cement $(\mathbf{K g})$ & Fly ash $(\mathbf{K g})$ & Fly ash content $(\mathbf{\%})$ & Water $(\mathbf{K g})$ \\
\hline A & 407.25 & 0.00 & 0 & 162.90 \\
B & 366.53 & 40.73 & 10 & 162.90 \\
C & 325.80 & 81.45 & 20 & 162.90 \\
D & 285.08 & 122.18 & 30 & 162.90 \\
E & 244.35 & 162.90 & 40 & 162.90 \\
\hline Group & Sand (Kg) & Gravel (Kg) & Water reducing agent content (\%) & Air-entraining agent content (\%) \\
\hline A & 710.67 & 1159.513 & 0.300 & 0.030 \\
B & 705.26 & 1150.683 & 0.390 & 0.085 \\
C & 699.85 & 1141.853 & 0.410 & 0.110 \\
D & 694.43 & 1133.023 & 0.445 & 0.160 \\
E & 689.02 & 1124.193 & 0.480 & 0.190 \\
\hline
\end{tabular}

Table 2. Symbol abbreviations and experimental conditions

\begin{tabular}{ccc}
\hline Symbol & F50-C3 & F100-C7 \\
\hline Meaning & $\begin{array}{c}\text { In each test cycle, the test pieces were subject } \\
\text { to freeze-thaw for 50 times first and fast } \\
\text { carbonization for 3 days later. }\end{array}$ & $\begin{array}{c}\text { In each test cycle, the test pieces were subject to } \\
\text { freeze-thaw for 100 times first and fast } \\
\text { carbonization for 7 days later. }\end{array}$ \\
Number of test cycles & 4 & 4 \\
Simulated geographic location & Qinghai-Tibet area & Northeast area \\
Average annual freeze-thaw cycles & 140 cycles & 121 cycles \\
$\mathrm{CO}_{2}$ concentration & $0.03973 \%$ & $0.03973 \%$ \\
Equivalent time & 17 years & 39 years \\
\hline
\end{tabular}




\section{CALCULATION METHOD OF RCA BASED ON IPP}

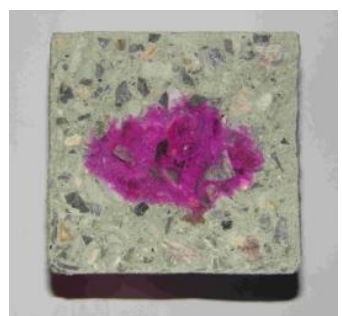

(a)

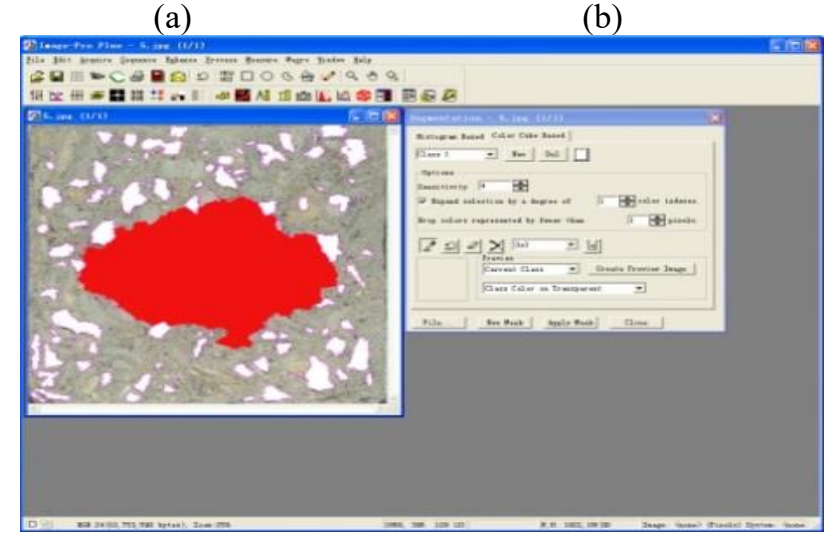

(c)

Figure 1. Images of carbonized area measured by IPP

The images were first processed by PS, and the equivalent carbonized area values were then measured by IPP. In this paper, the RCA is denoted as $\delta$, the total measured area is $A$, the non-carbonized area is $A_{f}$, the area of coarse aggregate in the carbonized area is $A_{c g}$, the carbonized area is $A_{t}$, and there is $A=A_{f}+A_{c g}+A_{t}$. The specific measurement and calculation steps of RCA are:
(1) The fracture surface was treated with phenolphthalein solution and then placed in a container with a white inner surface, after the color had changed $\left(A_{f}\right)$, pictures were taken by a high-definition digital camera, and original images were obtained (Figure 1a).

(2) The original images were processed by PS to reduce the errors, the coarse aggregate $A_{f}$ (the part on the fracture surface whose color hadn't changed) and the other parts $A_{t}$ were colored in different colors (Figure 1b).

(3) $A_{f}, A_{t}, A_{c g}$ were measured by IPP (Figure 1c).

(4) The RCA was calculated as: $\delta=A_{t} / A \times 100 \%=A_{t} /\left(A_{f}+\right.$ $\left.A_{c g}+A_{t}\right) \times 100 \%$.

As shown in the figures, the left and right sides of the test pieces were wrapped with paraffin wax, and the upper and lower sides were not processed.

\section{EXPERIMENTAL RESULTS AND ANALYSIS}

\subsection{Influence of freeze-thaw on RCA}

The experiments on the RCA for the two simulated regions of Qinghai-Tibet and Northeast were divided into two groups. The Qinghai-Tibet test groups adopted the CO (carbonizationonly) mode and the F50-C3 mode, and the Northeast test groups adopted the $\mathrm{CO}$ mode and the F100-C7 mode. The experimental data are shown in Table 3 and Table 4, respectively.

According to Tables 3 and 4, for concrete test pieces with different fly ash contents in the two simulated regions of Qinghai-Tibet and Northeast, the curves of RCA (under different modes) with carbonization age were plotted, as shown in Figures 2 and 3.

Table 3. RCA of fly ash concrete under $\mathrm{CO}$ and F50-C3 modes

\begin{tabular}{|c|c|c|c|c|c|c|c|}
\hline \multirow{2}{*}{ Group } & \multirow{2}{*}{ Fly ash content } & \multirow{2}{*}{ Mode } & \multirow{2}{*}{$\begin{array}{c}\text { Test } \\
\text { piece No. }\end{array}$} & \multicolumn{4}{|c|}{ Carbonization age(d) } \\
\hline & & & & 3 & 6 & 9 & 12 \\
\hline \multirow{2}{*}{ A } & \multirow{2}{*}{0} & $\mathrm{CO}$ & $\mathrm{A} 2-1$ & 0.019 & 0.043 & 0.068 & 0.096 \\
\hline & & $\mathrm{F} 50-\mathrm{C} 3$ & A2-3 & 0.048 & 0.091 & 0.115 & 0.166 \\
\hline \multirow{2}{*}{$\mathrm{B}$} & \multirow{2}{*}{$10 \%$} & $\mathrm{CO}$ & B2-1 & 0.116 & 0.126 & 0.131 & 0.150 \\
\hline & & $\mathrm{F} 50-\mathrm{C} 3$ & B2-3 & 0.123 & 0.154 & 0.177 & 0.206 \\
\hline \multirow{2}{*}{$\mathrm{C}$} & \multirow{2}{*}{$20 \%$} & $\mathrm{CO}$ & C2-1 & 0.155 & 0.170 & 0.185 & 0.196 \\
\hline & & $\mathrm{F} 50-\mathrm{C} 3$ & C2-3 & 0.170 & 0.185 & 0.206 & 0.234 \\
\hline \multirow{2}{*}{$\mathrm{D}$} & \multirow{2}{*}{$30 \%$} & $\mathrm{CO}$ & D2-1 & 0.177 & 0.201 & 0.228 & 0.254 \\
\hline & & F50-C3 & D2-3 & 0.178 & 0.217 & 0.267 & 0.311 \\
\hline \multirow{2}{*}{$\mathrm{E}$} & \multirow{2}{*}{$40 \%$} & $\mathrm{CO}$ & E2-1 & 0.205 & 0.277 & 0.294 & 0.317 \\
\hline & & F50-C3 & $\mathrm{E} 2-3$ & 0.240 & 0.315 & 0.361 & 0.393 \\
\hline
\end{tabular}

Table 4. RCA of fly ash concrete under CO and F100-C7 modes

\begin{tabular}{|c|c|c|c|c|c|c|c|}
\hline \multirow{2}{*}{ Group } & \multirow{2}{*}{ Fly ash content } & \multirow{2}{*}{ Mode } & \multirow{2}{*}{ Test piece No. } & \multicolumn{4}{|c|}{ Carbonization age(d) } \\
\hline & & & & 7 & 14 & 21 & 28 \\
\hline \multirow{2}{*}{ A } & \multirow{2}{*}{0} & $\mathrm{CO}$ & A2-4 & 0.048 & 0.082 & 0.119 & 0.157 \\
\hline & & $\mathrm{F} 100-\mathrm{C} 7$ & A2-6 & 0.058 & 0.089 & 0.137 & 0.196 \\
\hline \multirow{2}{*}{ B } & \multirow{2}{*}{$10 \%$} & $\mathrm{CO}$ & B2-4 & 0.137 & 0.166 & 0.198 & 0.220 \\
\hline & & $\mathrm{F} 100-\mathrm{C} 7$ & B2-6 & 0.159 & 0.189 & 0.203 & 0.243 \\
\hline \multirow{2}{*}{$\mathrm{C}$} & \multirow{2}{*}{$20 \%$} & $\mathrm{CO}$ & $\mathrm{C} 2-4$ & 0.171 & 0.195 & 0.216 & 0.246 \\
\hline & & F100-C7 & C2-6 & 0.196 & 0.216 & 0.257 & 0.289 \\
\hline \multirow{2}{*}{$\mathrm{D}$} & \multirow{2}{*}{$30 \%$} & $\mathrm{CO}$ & D2-4 & 0.201 & 0.235 & 0.239 & 0.279 \\
\hline & & F100-C7 & D2-6 & 0.235 & 0.265 & 0.301 & 0.357 \\
\hline \multirow{2}{*}{$\mathrm{E}$} & \multirow{2}{*}{$40 \%$} & $\mathrm{CO}$ & E2-4 & 0.213 & 0.267 & 0.305 & 0.355 \\
\hline & & $\mathrm{F} 100-\mathrm{C} 7$ & E2-6 & 0.265 & 0.317 & 0.365 & 0.453 \\
\hline
\end{tabular}


According to the curves in Figures 2 and 3, the values of RCA under the $\mathrm{CO}$ mode and FC mode all increased with the increase of carbonization age, and the sizes of the increment varied with the fly ash content and the experiment mode; for concrete test pieces with a same fly ash content, the FC mode curves were always above the $\mathrm{CO}$ mode curves, indicating that the RCA values of FC mode were higher than those of $\mathrm{CO}$ mode, the freeze-thaw cycles had an adverse effect on the carbonization of fly ash concrete, that is, freeze-thaw had aggravated the carbonization. Horizontal comparisons of the RCA values of concrete test pieces with different fly ash contents showed that, regardless of the $\mathrm{FC}$ mode or the $\mathrm{CO}$ mode, as the content of fly ash increased, the RCA increased as well, indicating that the higher the fly ash content, the greater the RCA value, and this trend was also true for the images in Figure 3.
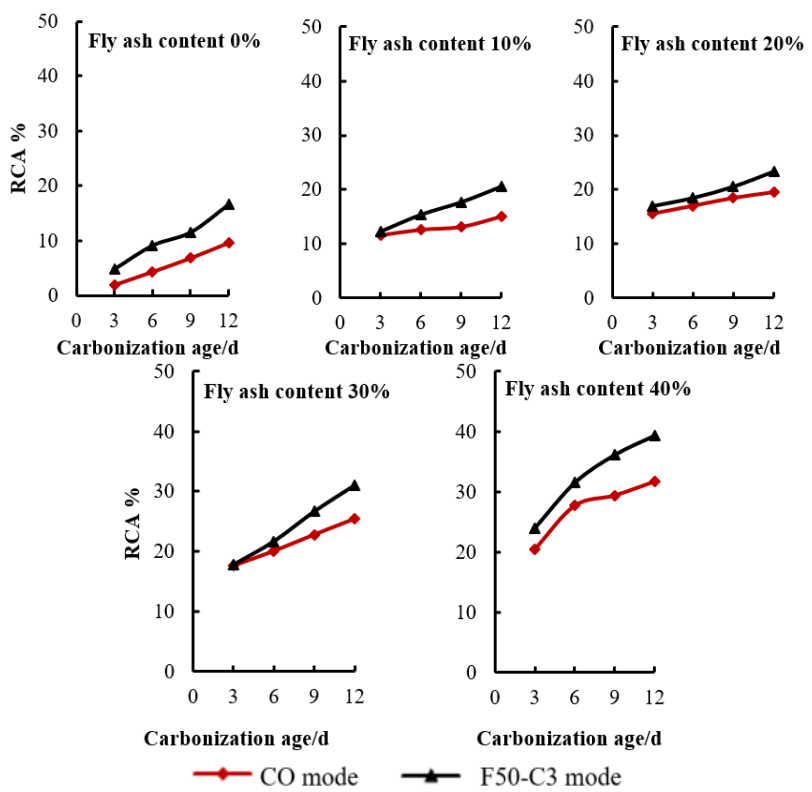

Figure 2. RCA-carbonization age curves of concrete test pieces with different fly ash contents under $\mathrm{CO}$ and F50-C3 modes

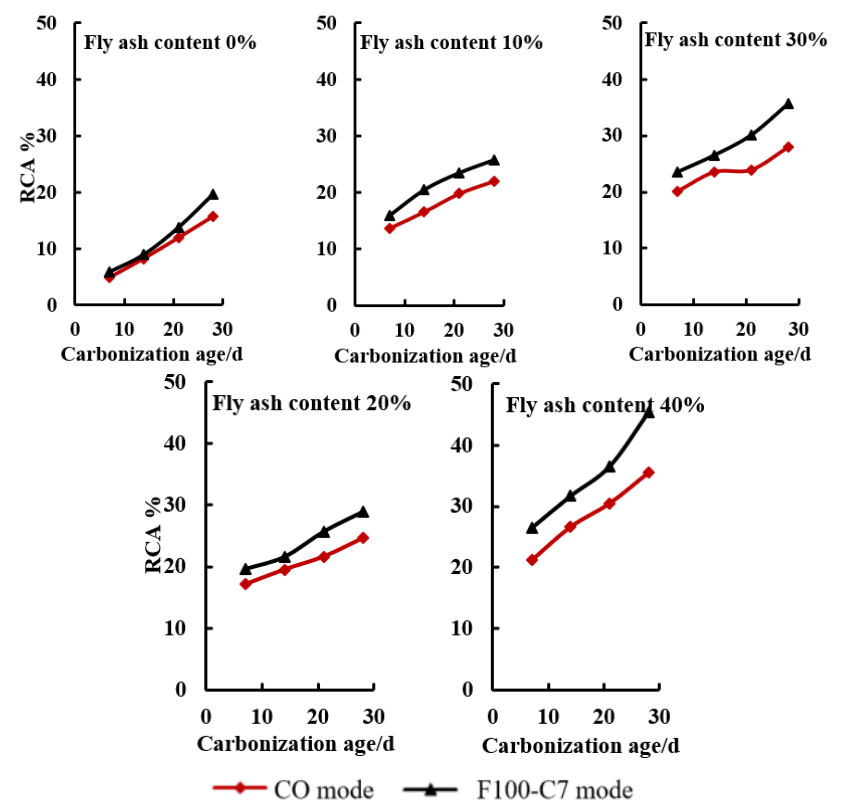

Figure 3. RCA-carbonization age curves of concrete test pieces with different fly ash contents under $\mathrm{CO}$ and F100-C7 modes

\subsection{Influence of fly ash content on RCA}

Figures 4, 5, and 6 showed the RCA-fly ash content relationship under $\mathrm{CO}$ mode, F50-C3 mode (Qinghai-Tibet), and F100-C7 mode (Northeast), wherein "FCxd" represents that the test pieces were subject to freeze-thaw cycles first and carbonized for $\mathrm{x}$ days later.

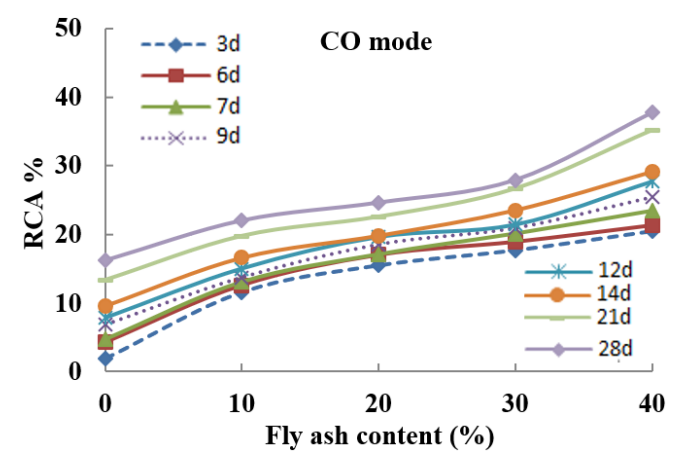

Figure 4. Relationship between RCA and fly ash content under $\mathrm{CO}$ mode

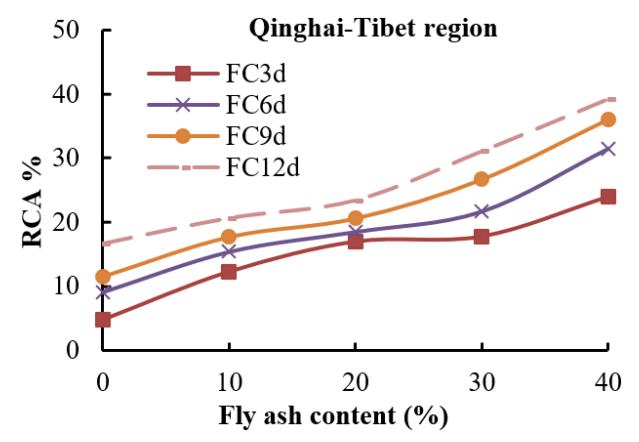

Figure 5. Relationship between RCA and fly ash content under F50-C3 mode

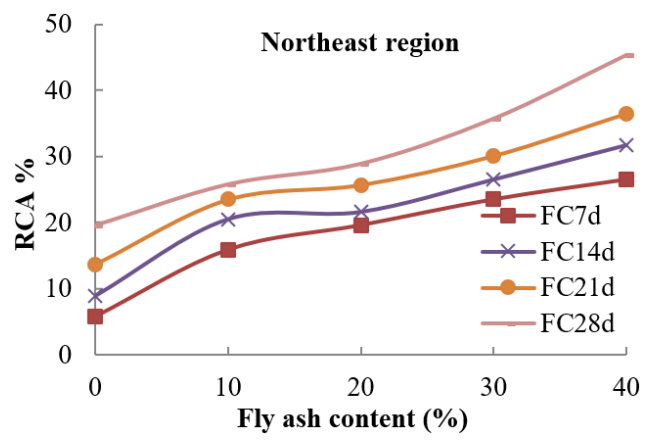

Figure 6. Relationship between RCA and fly ash content under F100-C7 mode

According to Figures 4, 5 and 6, RCA values of $\mathrm{CO}$ and FC modes all increased with the increase of fly ash content, and the curves showed a trend of convergence first and divergence later. When the content of fly ash was $20 \%$, the curve reached the convergence point. When the fly ash content was 0 , the concrete had the best carbonization resistance. When the fly ash content was between $10 \%$ and $30 \%$, the RCA increased slowly. When the content of fly ash was between $10 \%$ and $20 \%$, the RCA of fly ash concrete with older carbonization age increased slowly. When the content of fly ash was between $20 \%$ and $30 \%$, the RCA of fly ash concrete with younger carbonization age increased slowly. 


\subsection{Relationship between CRA and carbonization depth}

The carbonation depth of concrete under the $\mathrm{CO}$ and FC modes were measured, the data is shown in Table 5 and Table 6.

Carbonization depth and RCA can be regarded as two indicators of the carbonation resistance of concrete, and the two have a certain correlation. Figures 7 and 8 respectively show the relationship between carbonization depth and RCA under the $\mathrm{CO}$ and $\mathrm{FC}$ modes and under different fly ash contents. It can be seen from the figure that, regardless of the
CO or FC mode, overall, the carbonization depth and the RCA showed a linear relationship, which can be expressed as $\mathrm{D}=\mathrm{k} \delta+\mathrm{b}$, wherein $\mathrm{D}$ represents the carbonization depth, $\delta$ represents the RCA, and $b$ is a constant. Under the $\mathrm{CO}$ mode, the value of coefficient $k$ was between 30 and 35 , the relationship between carbonization depth and RCA can be approximately expressed as $\mathrm{D}=32 \delta$; under the $\mathrm{FC}$ mode, the value of coefficient $k$ was between 19 and 31, the relationship between carbonization depth and RCA can be approximately expressed as $\mathrm{D}=27.5 \delta-0.1$.

Table 5. Carbonation depth of fly ash concrete under CO and F50-C3 modes

\begin{tabular}{|c|c|c|c|c|c|c|c|}
\hline \multirow{2}{*}{ Group } & \multirow{2}{*}{ Fly ash content } & \multirow{2}{*}{ Mode } & \multirow{2}{*}{ Test piece No. } & \multicolumn{4}{|c|}{ Carbonization age(d) } \\
\hline & & & & 3 & 6 & 9 & 12 \\
\hline \multirow{2}{*}{ A } & \multirow{2}{*}{0} & $\mathrm{CO}$ & A2-1 & 0.5 & 1.3 & 2.0 & 2.9 \\
\hline & & $\mathrm{F} 50-\mathrm{C} 3$ & A2-3 & 0.3 & 1.8 & 2.5 & 3.8 \\
\hline \multirow{2}{*}{ B } & \multirow{2}{*}{$10 \%$} & $\mathrm{CO}$ & B2-1 & 3.2 & 3.5 & 4.1 & 4.5 \\
\hline & & F50-C3 & B2-3 & 3.2 & 3.8 & 4.9 & 5.5 \\
\hline \multirow{2}{*}{$\mathrm{C}$} & \multirow{2}{*}{$20 \%$} & $\mathrm{CO}$ & $\mathrm{C} 2-1$ & 4.6 & 5.2 & 5.7 & 6.0 \\
\hline & & F50-C3 & $\mathrm{C} 2-3$ & 4.8 & 5.4 & 5.9 & 6.3 \\
\hline \multirow{2}{*}{$\mathrm{D}$} & \multirow{2}{*}{$30 \%$} & $\mathrm{CO}$ & D2-1 & 5.0 & 6.5 & 6.8 & 7.1 \\
\hline & & F50-C3 & $\mathrm{D} 2-3$ & 5.2 & 6.5 & 7.0 & 7.5 \\
\hline \multirow{2}{*}{$\mathrm{E}$} & \multirow{2}{*}{$40 \%$} & $\mathrm{CO}$ & E2-1 & 6.1 & 6.8 & 8.0 & 8.7 \\
\hline & & F50-C3 & E2-3 & 6.1 & 7.3 & 8.5 & 9.7 \\
\hline
\end{tabular}

Table 6. Carbonation depth of fly ash concrete under CO and F100-C7 modes

\begin{tabular}{|c|c|c|c|c|c|c|c|}
\hline \multirow{2}{*}{ Group } & \multirow{2}{*}{ Fly ash content } & \multirow{2}{*}{ Mode } & \multirow{2}{*}{ Test piece No. } & \multicolumn{4}{|c|}{ Carbonization age (d) } \\
\hline & & & & 7 & 14 & 21 & 28 \\
\hline \multirow{2}{*}{$\mathrm{A}$} & \multirow{2}{*}{0} & $\mathrm{CO}$ & A2-4 & 1.4 & 2.6 & 3.9 & 4.4 \\
\hline & & F100-C7 & A2-6 & 1.8 & 3.1 & 4.5 & 5.3 \\
\hline \multirow{2}{*}{ B } & \multirow{2}{*}{$10 \%$} & $\mathrm{CO}$ & B2-4 & 4.5 & 5.3 & 6.6 & 7.5 \\
\hline & & $\mathrm{F} 100-\mathrm{C} 7$ & B2-6 & 5.2 & 6.1 & 7.1 & 7.8 \\
\hline \multirow{2}{*}{$\mathrm{C}$} & \multirow{2}{*}{$20 \%$} & $\mathrm{CO}$ & $\mathrm{C} 2-4$ & 5.5 & 6.4 & 7.2 & 8.0 \\
\hline & & $\mathrm{F} 100-\mathrm{C} 7$ & $\mathrm{C} 2-6$ & 5.9 & 7.1 & 8.3 & 8.9 \\
\hline \multirow{2}{*}{$\mathrm{D}$} & \multirow{2}{*}{$30 \%$} & $\mathrm{CO}$ & D2-4 & 6.2 & 7.5 & 8.0 & 9.2 \\
\hline & & F100-C7 & D2-6 & 6.8 & 7.8 & 8.6 & 10.0 \\
\hline \multirow{2}{*}{$\mathrm{E}$} & \multirow{2}{*}{$40 \%$} & $\mathrm{CO}$ & E2-4 & 6.7 & 8.1 & 9.0 & 10.3 \\
\hline & & F100-C7 & E2-6 & 7.1 & 8.8 & 9.6 & 11.2 \\
\hline
\end{tabular}

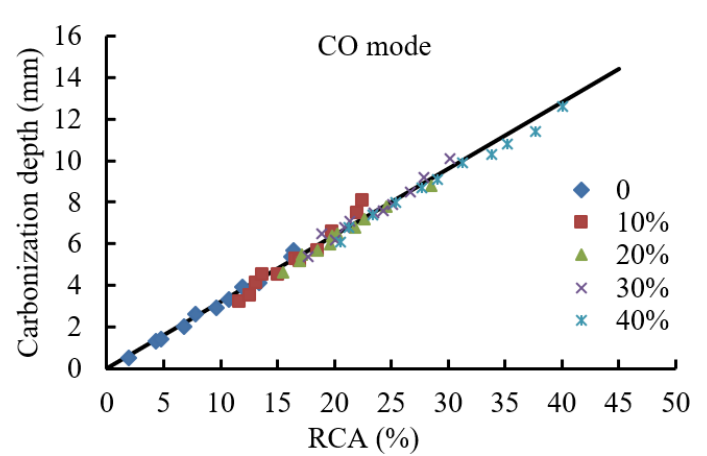

Equation of regression: $\mathrm{D}=32 \delta$

Figure 7. Relationship between carbonization depth and RCA under CO mode

\section{CONCLUSIONS}

(1) With the help of PS and IPP, this paper accurately measured the carbonized area of concrete and calculated the RCA (ratio of carbonized area), which was then taken as an indicator to characterize the concrete's resistance to carbonization, especially after the test pieces had been subject

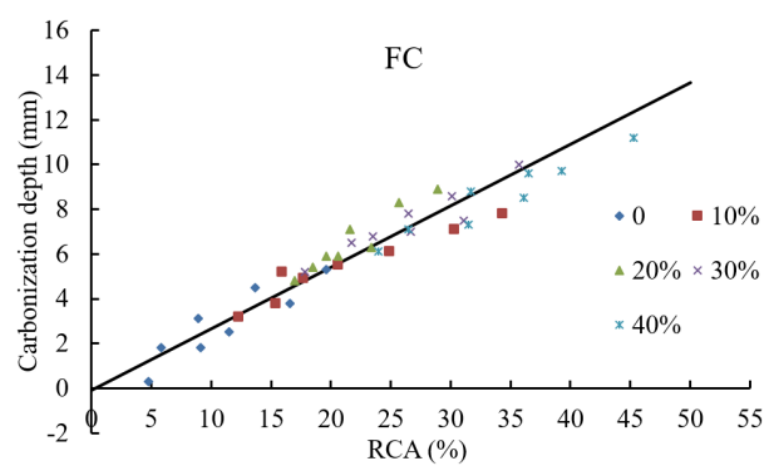

Equation of regression: $\mathrm{D}=27.5 \delta-0.1$

Figure 8. Relationship between carbonization depth and RCA under FC mode

to freeze-thaw cycles.

(2) Freeze-thaw cycles can aggravate carbonization, and the carbonization resistance of concrete under $\mathrm{CO}$ mode was better than that under the FC mode.

(3) When fly ash content was between $10 \%$ and $30 \%$, RCA increased slowly; when fly ash content was $20 \%$, the convergence point showed up; when fly ash content was 0 , the 
air-entrained fly ash concrete had the best resistance to carbonation.

(4) Regardless of $\mathrm{CO}$ or FC mode, there's a linear relationship between carbonization depth and RCA, which can be expressed as $\mathrm{D}=32 \delta$ and $\mathrm{D}=27.5 \delta-0.1$, respectively, and the formulas were in good agreement with the experimental results.

\section{ACKNOWLEDGEMENTS}

This research in this paper was supported by Project of Baoding City Science \&Technology: Study on durability of fly ash Concrete under Coupling Effect of Freeze-thaw and Carbonation (Grant No.: 2011ZG013); the Technology Foundation of Agricultural University of Hebei (No. LG201808); the Provincial Nature Science Foundation of Hebei Province: Study on concrete structure durability based on multi-factor coupling effect (Grant No.: E2015204111); and the Key Project of Provincial Education Department of Hebei Province: Study on durability of existing concrete structures underloading (Grant No.: ZD2016037).

\section{REFERENCES}

[1] Thomas, M.D.A., Matthews, J.D. (1992). Carbonation of fly ash concrete. Magazine of Concrete Research, 44(160): 217-228 https://doi.org/10.1680/macr.1992.44.160.217

[2] Khunthongkeaw, J., Tangtermsirikul, S., Leelawat, T. (2006). A study on carbonation depth prediction for fly ash concrete. Construction and Building Materials, 20(9): 744-753. https://doi.org/10.1016/j.conbuildmat.2005.01.052

[3] Jiang, L., Lin, B., Cai, Y. (2000). A model for predicting carbonation of high-volume fly ash concrete. Cement and Concrete Research, 30(5): 699-702. https://doi.org/10.1016/S0008-8846(00)00227-1

[4] Khunthongkeaw, J., Tangtermsirikul, S. (2005). Model for simulating carbonation of fly ash concrete. Journal of Materials in Civil Engineering, 17(5): 570-578. https://doi.org/10.1061/(ASCE)08991561(2005)17:5(570)

[5] Hussain, S., Bhunia, D., Singh, S.B. (2017). Comparative study of accelerated carbonation of plain cement and flyash concrete. Journal of Building Engineering, 10: 26-31. https://doi.org/10.1016/j.jobe.2017.02.001

[6] Lye, C.Q., Dhir, R.K., Ghataora, G.S. (2015). Carbonation resistance of fly ash concrete. Magazine of Concrete Research, 67(21): 1150-1178. https://doi.org/10.1680/macr.15.00204

[7] Lei, B., Li, W., Li, Z., Wang, G., Sun, Z. (2018). Effect of cyclic loading deterioration on concrete durability: Water absorption, freeze-thaw, and carbonation. Journal of Materials in Civil Engineering, 30(9): 04018220. https://doi:10.1061/(asce)mt.1943-5533.0002450

[8] Liu, M.H., Wang, Y.F. (2012). Damage constitutive model of fly ash concrete under freeze-thaw cycles. Journal of Materials in Civil Engineering, 24(9): 11651174. https://doi.org/10.1061/(ASCE)MT.1943-
5533.0000491

[9] Xiao, J., Gou, C.F. (2010). Overview of the research for concrete carbonation. Concrete, (1): 40-52. https://doi.org/10.3969/j.issn.1002-3550.2013.02.002

[10] Mao, M., Zhang, D., Yang, Q., Zhang, W. (2019). Study of durability of concrete with fly ash as fine aggregate under alternative interactions of freeze-thaw and carbonation. Advances in Civil Engineering, 2019: 4693893. https://doi.org/10.1155/2019/4693893

[11] Zhang, D., Mao, M., Yang, Q., Zhang, W., Han, P. (2019). Experimental investigation of neutralisation of concrete with fly ash as fine aggregate in freeze-thaw environment. Advances in Civil Engineering, 2019: 6860293. https://doi.org/10.1155/2019/6860293

[12] Niu, D., Xiao, Q., Zhu, W. (2012). Concrete damage and neutralization under coupling effect of carbonation and freeze-thaw cycles. Journal of Wuhan University of Technology-Mater. Sci. Ed., 27(2): 353-357. https://doi.org/10.1007/s11595-012-0465-8

[13] He, Z., Tang, S.W., Zhao, G.S., Chen, E. (2016). Comparison of three and one dimensional attacks of freeze-thaw and carbonation for concrete samples. Construction and Building Materials, 127: 596-606. https://doi.org/10.1016/j.conbuildmat.2016.09.069

[14] Li, X., Li, M. X., Shen, X.M., Yang, H.Q. (2014). Effect of carbonization impact on compressive strength of cement-fly ash mortar subjected to freeze-thaw cycles. Applied Mechanics and Materials, 454: 209-212. https://doi.org/10.4028/www.scientific.net/AMM.454.2 09

[15] Rao, M., Li, M., Yang, H., Li, X., Dong, Y. (2016). Effects of carbonation and freeze-thaw cycles on microstructure of concrete. Journal of Wuhan University of Technology-Mater. Sci. Ed., 31(5): 1018-1025. https://doi.org/10.1007/s11595-016-1484-7

[16] Liu, F., You, Z., Yang, X., Wang, H. (2018). Macromicro degradation process of fly ash concrete under alternation of freeze-thaw cycles subjected to sulfate and carbonation. Construction and Building Materials, 181: 369-380. https://doi.org/10.1016/j.conbuildmat.2018.06.037

[17] Kuosa, H., Ferreira, R. M., Holt, E., Leivo, M., Vesikari, E. (2014). Effect of coupled deterioration by freeze-thaw, carbonation and chlorides on concrete service life. Cement and Concrete Composites, 47: 32-40. https://doi.org/10.1016/j.cemconcomp.2013.10.008

[18] Chai, L., Guo, L., Chen, B., Xu, Y. (2018). Interactive effects of freeze-thaw cycle and carbonation on tensile property of ecological high ductility cementitious composites for bridge deck link slab. Construction and Building Materials, 186: 773-781. https://doi.org/10.1016/j.conbuildmat.2018.07.248

[19] Li, J.Y., Peng, X.P., Deng, Z.G., Cao, J.G., Guan, Y.S., Lin, L., Tian, J.T., Li, F., Wang, A.Q., Wang, Z.G., Peng, T., Cai, M.Z., Zhang, X.M. (2000). Quantitative design on the frost-resistance of concrete. Concrete, (9): 61-65. https://doi.org/10.3969/j.issn.1002-3550.2010.01.014

[20] Lin, C., Ou, J.P. (2013). Model and parameters of freezethaw action spectrum for the needs of structural life-cycle design. Journal of Natural Disasters, 22(4): 1-10. 